\title{
Endoscopic lithotripsy for right intrahepatic bile duct stone through endoscopic ultrasound-guided hepaticogastrostomy
}

Treatment for intrahepatic bile duct (IHBD) stones remains a challenge. Although endoscopic ultrasound (EUS)guided antegrade treatment for biliary stones has been reported recently [1,2], this method is indicated for stones in the common bile duct or left IHBD. For right IHBD stones, percutaneous transhepatic biliary drainage-guided treatment is usually performed. Herein, we describe an endoscopic treatment procedure for right IHBD stones through an EUS-guided hepaticogastrostomy (HGS) route.

A 74-year-old man who had undergone pancreaticoduodenectomy for pancreatic cancer was admitted to our hospital because of IHBD stones detected by computed tomography. The stones were located both in the left and right IHBD ( $\triangleright$ Fig.1). Single-balloon enteroscopeassisted endoscopic retrograde cholangiography showed the stones were trapped in segments 3 (B3) and 6 (B6) of the IHBD ( $\triangleright$ Fig. 2 ), and that the right posterior segmental duct drained into the left hepatic duct. Because neither a balloon catheter nor a basket catheter could be passed due to the biliary tree bending and the impacted stones, the treatment failed. We then performed EUS-HGS for B3 by using a plastic stent (Type IT; Gadelius Medical Co., Ltd., Tokyo, Japan) in order to create a treatment route ( $\mathbf{F i g} \mathbf{3}$ )

The patient was readmitted 1 month later for stone removal via the HGS route. First, we attempted to treat the B6 stone. We placed the guidewire in B6 by using a catheter with bendable tip (Swing Tip; Olympus Medical Systems, Tokyo, Japan). We were then able to insert a mechanical lithotripter (Litho-

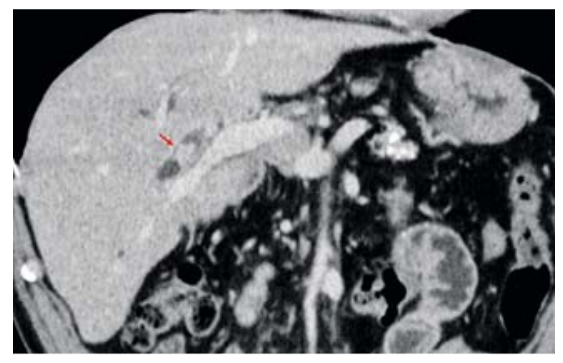

- Fig. 1 On computed tomography, the stone was located in segment 6 of the right intrahepatic bile duct (red arrow).

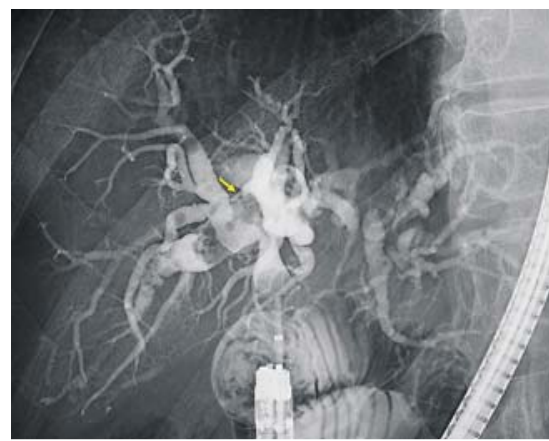

- Fig. 2 On single-balloon enteroscopeassisted endoscopic retrograde cholangiography, the large stone was seen in segment 6 of the right intrahepatic bile duct (yellow arrow).

Crush V; Olympus Medical Systems), and succeeded in crushing the B6 stones ( $\triangleright$ Fig.4, $\triangleright$ Video 1). Finally, we placed the plastic stent (Type IT) again for the next treatment.

This case suggests that endoscopic treatment through an EUS-HGS route can be useful even for right IHBD stones.

Endoscopy_UCTN_Code_TTT_1AR_2AH

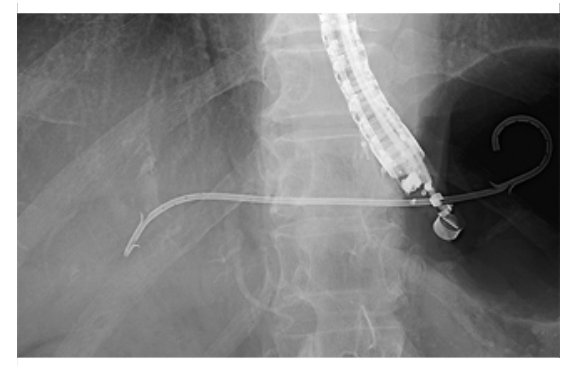

- Fig. 3 Endoscopic ultrasound-guided hepaticogastrostomy was performed using a plastic stent.

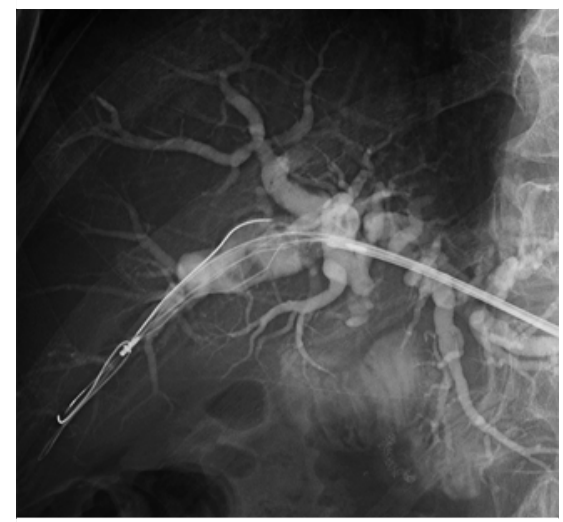

- Fig. 4 Mechanical lithotripsy through the hepaticogastrostomy was performed for the stones in segment 6 of the right intrahepatic bile duct.

Competing interests

None

The authors

Koichiro Mandai, Koji Uno, Kenjiro Yasuda Department of Gastroenterology, Kyoto Second Red Cross Hospital, Kyoto, Japan 


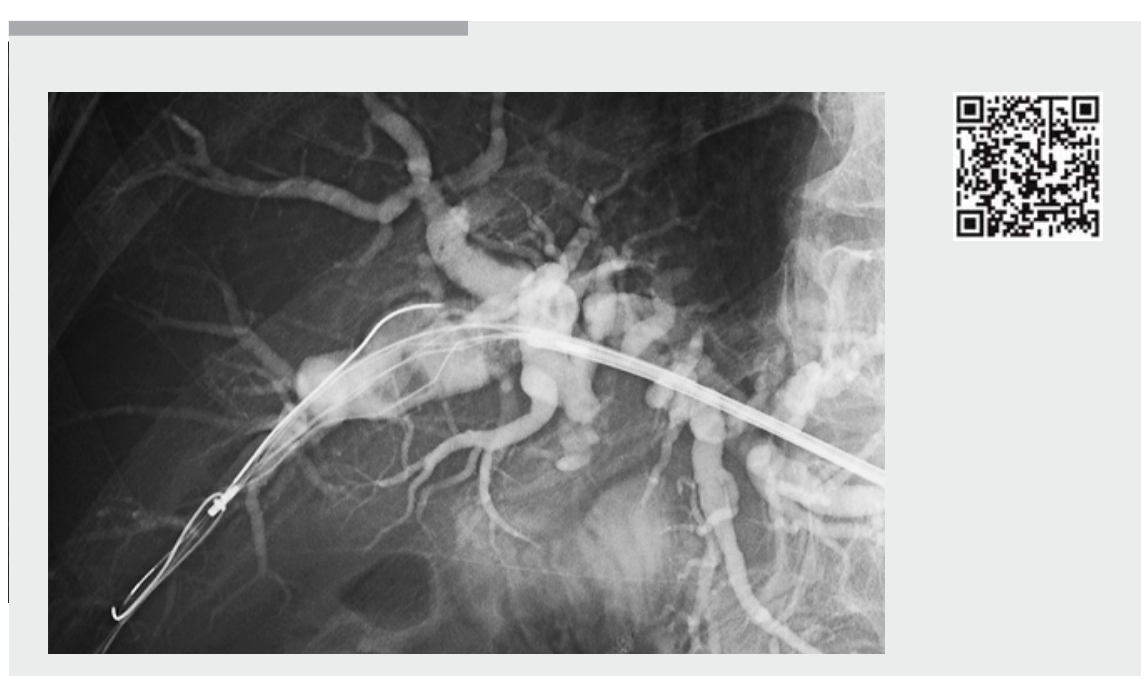

$\checkmark$ Video 1 Mechanical lithotripsy via hepaticogastrostomy.

\section{Corresponding author}

\section{Koichiro Mandai, MD}

Department of Gastroenterology, Kyoto Second Red Cross Hospital, 355-5 Haruobicho, Kamigyo-ku, Kyoto 602-8026, Japan Fax: +81-75-2563451

mndkchr@gmail.com

\section{Bibliography}

DOI https://doi.org/10.1055/a-0800-8429

Published online: 11.12.2018

Endoscopy 2019; 51: E40-E41

(c) Georg Thieme Verlag KG

Stuttgart · New York

ISSN 0013-726X

\section{ENDOSCOPY E-VIDEOS}

https:/|eref.thieme.de/e-videos

口. Endoscopy E-Videos is a free access online section, reporting 回制: on interesting cases and new techniques in gastroenterological endoscopy. All papers include a high quality video and all contributions are freely accessible online.

This section has its own submission website at https://mc.manuscriptcentral.com/e-videos 